\title{
Role of Religious Leaders in COVID-19 Prevention: A Community-Level Prevention Model in Sri Lanka
}

\author{
Millawage Supun Dilara Wijesinghe ${ }^{1}$ (D) . Vinya S. Ariyaratne ${ }^{2}$. \\ Balangoda Muhamdiramlage Indika Gunawardana ${ }^{1}$. \\ R. M. Nayani Umesha Rajapaksha ${ }^{1}$ - W. M. Prasad Chathuranga Weerasinghe ${ }^{1}$. \\ Praveen Gomez ${ }^{3}$. Sahani Chandraratna ${ }^{4} \cdot$ Thirupathy Suveendran $^{4}$. \\ R. P. Palitha Karunapema ${ }^{1}$
}

Accepted: 9 November 2021 / Published online: 23 November 2021

(C) The Author(s), under exclusive licence to Springer Science+Business Media, LLC, part of Springer Nature 2021

\begin{abstract}
The COVID-19 pandemic has affected all countries irrespective of their state of development. In countries with traditional societies, religious leaders have been acknowledged as key stakeholders in community engagement activities, including disease prevention. A community-level prevention model was established in 2020 by the Health Promotion Bureau (HPB), Sri Lanka, which incorporated mobilisation of the clergy to support the prevention and response schemes to COVID-19 with non-governmental stakeholders. This model was part of a more extensive community engagement network established by the HPB in cooperation with the country offices for WHO and UNICEF. Building trust, empowering behavioural traits applicable to minimise risks from COVID-19, leadership and coordination, message dissemination, addressing stigma and discrimination, supporting testing procedures, contact tracing activities and vaccination, building community resilience, spiritual and psychosocial support, and welfare provision are some of the useful factors that were identified in the model. Furthermore, a much broader and holistic approach is needed to focus on health behaviours and social and cultural aspects in a multi-faceted nature. This paper highlights a novel COVID-19 prevention model with active involvement of religious leaders that can be implemented in low resource settings. Our experience from Sri Lanka demonstrates the feasibility of implementing this model to mitigate the disastrous situation following the COVID-19 outbreak.
\end{abstract}

Keywords COVID-19 $\cdot$ Public health $\cdot$ Religious leaders $\cdot$ Community engagement Community-level prevention model $\cdot$ Community health planning $\cdot$ Community networks

Millawage Supun Dilara Wijesinghe dr.wijesinghe@gmail.com

Extended author information available on the last page of the article 


\section{Introduction}

The COVID-19 pandemic crippled the world with devastating consequences. Currently, the only preventive measures include key positive protective behaviours, movement restrictions, and vaccination. However, maintaining positive behavioural traits and socially learned behaviours related to disease prevention is dependent on how individuals and communities are motivated and educated. Furthermore, certain communities are at higher risk of developing worse clinical outcomes due to COVID-19 (Pan et al., 2020).

World history reports both positive and negative impacts on infectious diseases by religious norms, practices, and observances. Different religions historically have a different take on contagious diseases. However, in general, all religions are in favour of helping to improve conditions of the sick (Pennisi, 2011), even though there is a fine balance between pandemic control measures and religious behaviours and observances (Knight et al., 2021). According to Hong and Handal (2020), religious truths (that are found in sacred writings or religious traditions), scientific truths (that are anchored on data and explorations), and government policies (values expressed during the times of epidemics and pandemics) are not mutually exclusive and should not be held in an all-or-nothing manner. The authors further reiterate that science, religions, and governments should work in unison for the common good and well-being of all. In addition, religion can be argued as a social determinant of health in the pandemic's present context with both beneficial and harmful effects (Kawachi, 2019).

Other than the individual's health, COVID-19 pandemic affects the economy, society, politics, legal, and culture. Individuals have different reasons for not following preventive behaviours, underpinned by individual-specific, structural, and economic and socio-cultural factors. It is essential to address these factors at both macro- and micro-social levels. In this regard, making involvements of both celebrities and the clergy in COVID-19 confrontation activities has been observed in different countries, while Iran is one of the countries that has taken their support to immeasurable levels (Soleimanvandi Azar et al., 2021; Yoosefi Lebni et al., 2021).

There are, however, pros and cons of taking their support for COVID-19 confrontation activities. On the one hand, the positive role expected from the clergy is bringing in support for health promotion and spiritual activities, mobilisation of people to combat the disease, and material/instrument supports. On the other, opposing social restrictions, especially for closing religious places, countering the hygienic scientific principles, and inducing vaccine hesitancy, can be considered as adverse effects of the role of the clergy (Soleimanvandi Azar et al., 2021; Yoosefi Lebni et al., 2021).

According to various levels of health promotion deployable to address the COVID-19 pandemic, the downstream level focusses on individual-scale behaviour change (that can be accomplished through enabling), midstream level on organisation and communities (that can be achieved through advocacy and mediation), and finally the upstream level on policies (that can be achieved through 
advocacy) affecting the whole population (Brownson et al., 2010; Potvin \& Jones, 2011; van den Broucke, 2020). Religious clergy and faith-based organisations have a pivotal role in all three levels during the COVID-19 pandemic. Faith leaders have been noted to have an immense influence on people's health-related social behaviours (Heward-Mills et al., 2018) and play a key role in strengthening community participation during a pandemic (Marston et al., 2020). Furthermore, according to Hong and Handal (2020), collective efforts administered on the general public by Religion, Sciences, and Governing Authorities in combination have helped to fight many pandemics in history.

\section{COVID-19 Prevention and Religion}

The importance of religion can be argued in many ways how likely people will become infected by COVID-19 (due to religious activities), religion as a "problem" with regard to COVID-19 control, and lessons we can learn from the intersection of faith and infectious disease (Barmania \& Reiss, 2020). In the current COVID-19 pandemic, there have been many significant instances where religious norms, practices, and observances lead to increased disease spread and exposure. These barriers to better public health can be broadly listed as super-spreader events, religious festivals, gatherings during religious observance and prayers, and burial practices.

\section{Super-Spreader Events, Gatherings, and Religious Activities}

From the beginning of the pandemic, many countries delayed the initiation of lockdown measures, which resulted in mass gatherings and religious events. Such super-spreader events are defined as events, in which an unusually large number of secondary cases are infected by an individual (Majra et al., 2020). During COVID19, religious occurrences leading to super-spreader events have been reported in many countries such as South Korea, Germany, the USA, Netherlands, Singapore, and Hong Kong, including in Sri Lanka during the early phase of the pandemic (Ranawana, 2020). The number of infected due to these events ranges from 19 to 4531 (Majra et al., 2020). However, the alarming fact to note is that mass gathering religious events were continued amidst numerous government restrictions even in 2021, even when the disease spread was at its highest (Press Trust of India, 2021).

\section{Religious Festivals}

Religious festivals are another mode of COVID-19 spread. Religious congregations during these festivals are potential focal points for the dispersion of pathogens (Quadri, 2020). These events may lead to super-spreader events (Majra et al., 2020), and there is a clear association shown between early suspension of religious events and lower occurrence of COVID-19 infections (Quadri, 2020). The Sri Lankan Government and health authorities adopted this strategy by cancelling all prominent Buddhist, Christian, Hindu, and Muslim religious festivals and limiting the celebration to homes (UCA News, 2021a, 2021b). Although cancelling religious festivals 
leads to reducing the number of cases in many instances, a lack of coordination was seen as one of the key drawbacks.

\section{Burial Practices}

Each religion has its own way of burial practices. However, the pandemic restricted the communities and religious leaders in performing death and burial rituals. Individuals were given a shorter time to hold wakes; the number of attendees was limited, and some religious communities were forced to cremate the deceased against their religious teachings and doctrinal recommendations (Sarmiento, 2020). The protocols changed over time based on country-specific guidelines and taking into consideration the WHO Guidelines (World Health Organization, 2020a). The initial decision of Sri Lankan authorities was to cremate bodies irrespective of religious beliefs, which was later changed based on scientific evidence (BBC News, 2021a, 2021b), highlighting an exceptionally fine balance between respect for modern science and allowing spiritual practices which every country must strive to achieve (Sarmiento, 2020).

\section{Community Participation}

Another viewpoint regarding religion and COVID-19 is how it affects community participation. Community participation is vital for initiating a collective response by community to the disease, such as compliance with lockdown, steps to take during restrictions and supporting communities through volunteering (Marston et al., 2020). Gilmore and others, however, argue that community engagement should be context-specific to facilitate cultures, traditions, customs, social norms, and collective beliefs. The authors further report that working with religious leaders plays a crucial role in engaging communities from designing and planning interventions to trust-building, social and behaviour change communication, risk communication, surveillance tracing, logistic provision, and administration (Gilmore et al., 2020).

\section{Methods}

\section{A Model for Religious Leader Engagement: Health-Interfaith Community-Based Organisation (CBO) COVID-19 Prevention Model}

In Sri Lanka, the first patient with a local transmission was reported on 11 March 2020, following which COVID-19 prevention measures were put in place from 12 March onwards. Since then, Health Promotion Bureau (HPB) of the Ministry of Health, Sri Lanka, has served as the focal point in risk communication. The messages on protective behaviour were delivered through multiple platforms, including mass media, social media, traditional media (e.g., billboards), print media (e.g., stickers), "Suwasariya" emergency response teams, mobile phone ring tones, mobile text messages, and through provincial/district control teams directly and via Health 
Education Officers platform. In addition, the HPB also provided technical guidance and assistance in developing Information, Education, and Communication (IEC) material to other health institutions like Port Health Authorities.

A community-level prevention model was established in 2020 by the HPB during the first wave in Sri Lanka, which incorporated the mobilisation of religious leaders towards prevention of COVID-19. The model included the HPB, Sarvodaya Movement, Alliance Development Trust, and other community-based organisations (CBOs) at grassroot-level preventive health areas called "medical officer of health" level. This model was part of an extensive community engagement network established by the HPB at the national and regional level with WHO and UNICEF. This model was included in the "Risk Communication Community Engagement" (RCCE) framework developed by the HPB. The stakeholders to be included in the model were decided by several rounds of consultative meetings with the Ministry of Health and NGOs. The overview and role of each identified stakeholder are listed in Table 1.

The modes of operation were mobilising religious leaders of all faiths to promote nine identified health behaviours, namely to develop model community settings in

Table 1 Overview and roles of stakeholders in the Health-Interfaith-CBO COVID-19 prevention model

\begin{tabular}{|c|c|}
\hline Stakeholder & Overview and role of the stakeholder \\
\hline Health Promotion Bureau (HPB) & $\begin{array}{l}\text { The HPB is the centre of excellence for health communication, health } \\
\text { education and promotion. The HPB currently has approximately } \\
7000 \text { Mothers Support Groups (MSG) in all Medical Officer of } \\
\text { Health areas with a vast Happy Village Health volunteer force } \\
\text { network. The MSG's/happy villages are community empowerment } \\
\text { groups established to promote the health and well-being of commu- } \\
\text { nities. The coordination of activities of these groups is done at both } \\
\text { the central level (by HPB) and district level (via Health Education } \\
\text { Officers). National/district/ Medical Officer of Health level coordi- } \\
\text { nator. Overall monitoring and evaluation of the work conducted }\end{array}$ \\
\hline
\end{tabular}

Sarvodaya Movement

The Sarvodaya Movement is the largest national non-governmental organisation and community-based organisation in Sri Lanka, which plays an active role in over 15,000 villages across all 25 districts. Sarvodaya has a strong presence in all districts with adequate staffing, infrastructure, human resources, logistics and over 61 years of experience in community mobilisation and community leadership. Medical Officer of Health level implementer

Alliance Development Trust

Alliance Development Trust is also a non-governmental organisation working with an interfaith forum of religious leaders (including all religions) in communities with experience in stigma prevention and supporting community-based screening for leprosy. They also have a district-level network with Medical Officer of Health level volunteer workers. Medical Officer of Health level implementer

Community-Based Organisations

CBOs are working at the Medical Officer of Health level to support the communities in COVID-19 prevention. Medical Officer of Health level implementer/s

WHO/UNICEF

Technical support and resource mobilisation of the activities and overall monitoring and supervision of the work conducted 
religious places, to involve vulnerable groups in discussions, strengthen community leadership, to distribute IEC materials via community networks, and to monitor and evaluate the community engagement activities. This model was put into place in all 25 districts of the country from June 2020. The model dynamics are illustrated in Fig. 1.

The data about the conducted activities were collected in multiple ways. First, the village-level activity data were compiled by the religious leaders and community influencers of the Sarvodaya Movement and Alliance Development Trust. Second, the collected data were directly communicated to the HPB during regular online monthly meetings. Third, the HPB separately collected data via the Health Education Officers network. This network is monitored through weekly online meetings held by the HPB. The tools used were mainly online meetings and social media.

\section{Results}

Ten major themes are discussed in terms of results namely:

- Mobilising religious leaders in the model: success factors

- Trust building and empowerment for COVID-19 appropriate behaviours

- Leadership and coordination

- Message dissemination

- Addressing stigma and discrimination

- Testing procedures and contact tracing activities

- Vaccination

- Building community resilience

- Spiritual and psychosocial support

- Welfare Provision

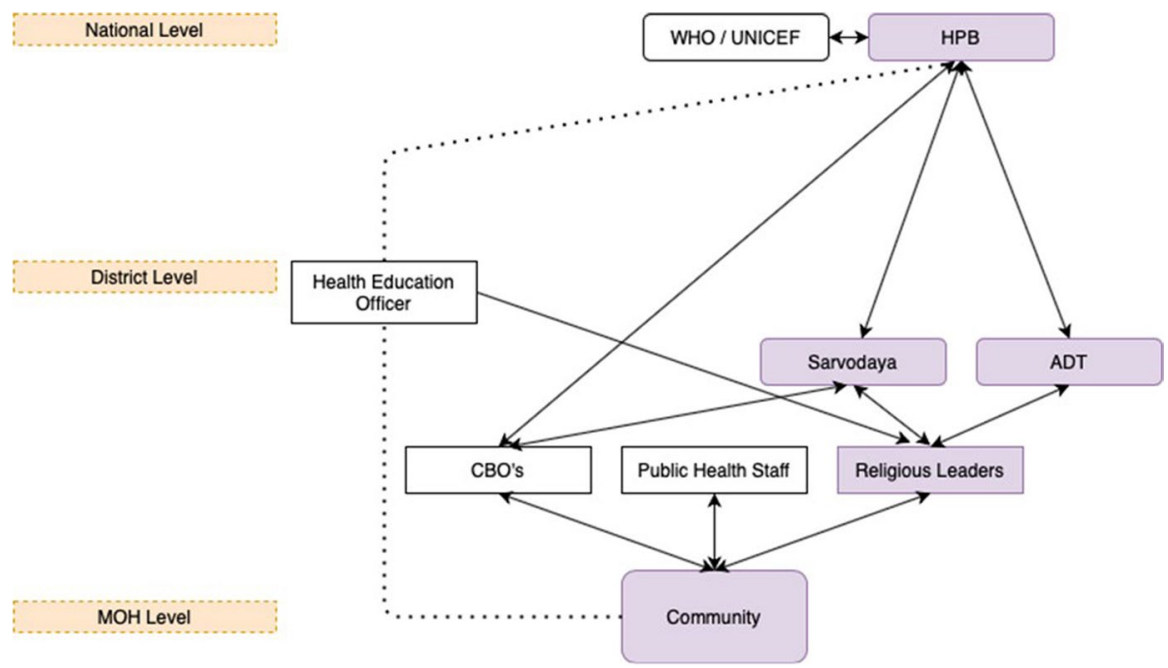

Fig. 1 Health-Interfaith-CBO COVID-19 prevention model 


\section{Mobilising Religious Leaders in the Model: Success Factors}

To control the COVID-19 pandemic, mere scientific understanding of the disease is not sufficient. Instead, a much broader and holistic approach focusing on health behaviours and social and cultural aspects in a multi-faceted nature is required (Barmania \& Reiss, 2020). We have identified some areas that will be useful to uppermiddle-income counties (UMIC) in mobilising religious leaders for COVID-19 prevention in view of community engagement in our model. However, the readers need to understand that although Sri Lanka is categorised as a UMIC country, it has a robust public health infrastructure up to the grassroot level (Fernando, 2000).

\section{Trust Building and Empowerment for COVID-19 Appropriate Behaviours}

One of the key activities of risk communication involves building trust with the public regarding community participation (Marston et al., 2020; Tony Blair Institute for Global Change, 2020). Trust building was achieved early in the pandemic by the HPB by sharing timely and trustworthy health statistics and preventive behaviours via social media and the official website. This activity was later expanded to other groups using the present model, such as religious leaders communicating COVID19 appropriate behaviours to the public through regular meetings, through which trust was established in COVID-19 appropriate behaviours messages shared by the HPB.

One of the key activities promoted during the discussions was modelling positive behaviours in their places of worship and asking the followers to practise the same. These activities were supported by Sarvodaya and other CBOs at the district level. Contextualising COVID-19 appropriate behaviours with religious underpinnings to support public health measures helped in certain religions like Islam (by taking quotes such as Bukhari (186), Muslim (235) about washing hands; self-isolation-Bukhari (5771), Muslim (2221); staying at home-Haakim (2345), Bayhaqi (11,284); travel bans-Bukhari (5739,5730,6973), and Muslim (2219)) even during turbulent times with respect to burial practices (BBC News, 2021a, 2021b).

\section{Leadership and Coordination}

In conjunction with health authorities, religious leaders can support and coordinate awareness campaigns and mobilise communities for COVID-19 appropriate behaviours and vaccination (Gilmore et al., 2020). They can also provide leadership at the community level to promote COVID-19 prevention activities in hard-to-reach vulnerable communities. According to the proposed model, the already available Sarvodaya and Interfaith forum networks were utilised for activities across the country. Religious leaders supported the health authorities to maintain COVID-19 appropriate behaviours such as maintaining physical distance, hand hygiene, and proper usage of face masks during religious festivals and regular prayer activities. They also influenced communities to comply with government regulations during weddings and funeral practices. 
In addition, religious leaders were involved in providing leadership in planning COVID-19 prevention activities supported by CBOs. Religious leaders were trained online by the HPB and Sarvodaya regularly, which was supported by WHO. During these training sessions, each religious leader was empowered to maintain COVID19 appropriate behaviours in their places of worship. Each faith has different religious practices. Nevertheless, each religious leader was shown how to comply with the government regulations taking examples from real-world case scenarios. The religious leaders were shown success stories from other countries during these trainings.

Furthermore, these trainings were helpful in constantly keeping in touch with local health authorities and staying updated on current policies. The trainings also facilitated building networks (national, provincial, and district and community level) to maintain COVID-19 appropriate behaviours at the village level (Tony Blair Institute for Global Change, 2020). Via the interfaith and Sarvodaya networks, religious leaders were also influential in advocating for communities and community leaders to follow government and health authority restrictions in the country.

\section{Message Dissemination (Counter-Messaging and Managing Misinformation and Disinformation)}

Religious leaders in the proposed networks were requested to send and amplify key health messages developed by HPB to the public. These networks were helpful to communicate with previously unreached populations. On average, over 30,000 families were reached weekly by the interfaith network with appropriate behaviour messages. Over fifty faith leaders engaged every week in this task.

The religious leaders' network of Sarvodaya was trained online on addressing misinformation and disinformation; therefore, the influential religious leaders could counter the message if the wrong information was spreading in communities and social networks. They also educated other religious members and laypeople about checking the reliability of COVID-19 messages. The training, nuanced through the religious leaders' own pastoral background, was useful for dispelling religiously grounded misinformation and disinformation, which put communities at risk (Tony Blair Institute for Global Change, 2020).

The interfaith network was used as a surveillance network for misinformation and disinformation by regularly informing HPB of prevailing miscommunications. These information sources helped to strengthen social media responses regarding COVID-19 by the HPB. They supported the built-in influencer networks to dispel misinformation and disinformation related to COVID-19.

\section{Addressing Stigma and Discrimination}

Since the beginning of the pandemic, there have been negative perceptions towards persons infected with COVID-19 and their families. Stigma can be defined as (visible) characteristics of an individual that make them feel degraded and consider themselves unfit for inclusion in society (Bhanot et al., 2021). Regarding COVID-19, 
these characteristics include testing positive for the disease or having a family member who has been tested positive.

Furthermore, stigma can occur due to lack of knowledge (source of infection, protective measures), insufficient scientific understanding of the disease, fear mongering and passing the responsibility of spreading the disease to others, by the projection of negative sentiments targeted at groups of people and attributing the cause of illness as the irresponsibility of the infected person (Saeed et al., 2020).

At the beginning of the pandemic, the stigma associated with COVID-19 in Sri Lanka was significant. It was reflected in society when many health staff were denied entry to their rental places because they were working in COVID-19 treatment centres. In addition, Muslim communities were disparaged from rest of the society, in the early part of the pandemic, holding them allegedly responsible for spreading the disease. Prevention of stigma and discrimination of those testing positive and supporting families and contacts of people who have tested positive was oriented as a government initiative by the Ministry of Health, Sri Lanka. The model proposed by the HPB supported this activity.

In addition, training on preventing stigma and discrimination was conducted online for community volunteers and religious leaders by the Sarvodaya religious network. The religious leaders were trained on taking counter measures to tackle hate messages against groups and were encouraged to lead by example. Religious leaders were also instrumental in supporting health authorities to identify vulnerable people and communities in their areas.

\section{Testing Procedures and Contact Tracing Activities}

Testing for COVID-19 plays an important role in recognising people with the disease and identifying asymptomatic individuals who can spread the disease (Binnicker, 2020). Nevertheless, due to stigma, discrimination, and many other associated reasons, some individuals in Sri Lanka were reluctant to get tested for COVID-19. The interfaith network along with Sarvodaya was instrumental in resolving these issues in smaller communities, with religious leaders taking the lead in supporting health authorities (Berkley Center for Religion Peace \& World Affairs and World Faiths, 2020). As a result, they were able to build trust in hard-to-reach vulnerable communities in certain districts in Sri Lanka.

The HPB of Sri Lanka had regular discussions with the religious leaders and interfaith networks. Encouraging followers to get tested if required, dispelling misinformation and disinformation about testing, and advising religious leaders to direct communities to correct and reliable information sources about testing procedures were the activities promoted during the discussions. Religious leaders were also instrumental in supporting health authorities during contact tracing by building trust and alleviating fear in the communities. They were able to help families under quarantine through provision of correct information, countering stigma and discrimination, and encouraging others to get tested while reducing the tension between public health officials and communities by acting as mediators in prevention activities. 


\section{Vaccination}

It has been identified that religious leaders also play a significant role in any vaccination campaign (Oyo-Ita et al., 2021; Ruijs et al., 2013). Religious leaders can guide communities to correct and reliable information sources about vaccines and vaccination. They can also encourage an individual to get themselves vaccinated. The Health Promotion Bureau started the process of sharing vaccine information prior to the vaccination initiative. The information-sharing process was driven by the evidence collected from a vaccine acceptance survey conducted in the country (Wijesinghe et al., 2021) Furthermore, a community engagement guide (Health Promotion Bureau et al., 2021) was created for community leaders, religious leaders, and influencers with the collaboration of UNICEF and Sarvodaya. The key leaders of the interfaith network were briefed about vaccination and attended a meeting organised by Alliance Development Trust (ADT) and Health Promotion Bureau with the support of WHO.

\section{Building Community Resilience}

Building community resilience during the pandemic is a critical area that decides a community's persistent ability to overcome and recover (Yip et al., 2021). Sarvodaya was primarily responsible for work in partnership with communities to mitigate the effects of COVID-19. Sarvodaya, with other CBOs, was working closely with donor institutions to minimise the socio-economic impact (Berkley Center for Religion Peace \& World Affairs and World Faiths, 2020). Importantly, the WHO supported this activity with a special emphasis on vulnerable communities. Moreover, the routine surveys measured the socio-economic impact due to COVID-19 prior to many trainings conducted by the HPB. Both the Interfaith and Sarvodaya networks mobilised religious leaders in community resilience-building activities.

\section{Spiritual and Psychosocial Support}

Religious and faith communities have been providing means for coping, surviving, and raising hope during the era of pandemics (Hong \& Handal, 2020). Spiritual and psycho-social support to communities during the COVID-19 pandemic is a critical area that cannot be overlooked. Majority of the population struggled with the lockdown measures and movement restrictions, alongside the testing and contact tracing procedures. Traditional coping mechanisms are insufficient in a period of prolonged physical distancing. Instead, spiritual and psychosocial support is extremely important for people who are living alone, disadvantaged, or elderly (World Health Organization, 2020b). The religious leaders of the interfaith network kept people connected while adhering to the government policies of religious restrictions (movement restrictions, gatherings, social distancing, and prayer services). During spiritual activities, COVID-19 appropriate behavioural message dissemination was also done. Further, Interfaith networks supported communities when religious harmony 
was threatened (Berkley Center for Religion Peace, World Affairs \& World Faiths, 2020).

\section{Welfare Provision}

Religious leaders form an essential link in the safety net for vulnerable people (WHO, 2020a) who can assist with emergency aid to the poor in local communities or institutions where the religious hierarchy functions acting as a distribution hub for resources raised through voluntary donations (Arruda, 2020). For example, during the early phase of the pandemic, the interfaith network was involved in providing dry rations to vulnerable communities as emergency aid. They also actively supported the health and other state authorities in the provision of food and water. In addition, many religious leaders were encouraging followers to help and donate necessary food and medication to needy communities. Many media institutions in the country publicised this activity. Unfortunately, this voluntary support and active involvement were not seen, with the same scale of enthusiasm, during the second and third waves of the pandemic.

\section{Discussion}

\section{Remaining Challenges}

Most religions are based on "beliefs" while science is based on "facts". Therefore, conflict situations can occur when explaining concepts based on scientific facts. Epistemology intends to interpret the world through the values and viewpoints of each group (Hong \& Handal, 2020). The conflict between cremation and burial of dead bodies following COVID-19 was one instance. Comparing religious viewpoints against scientific truth will lead to conflicts since each approach has its own method and place for a reason. These extremes tend to cause confusion, leaving people feeling helpless and confused, ultimately resulting in spiritual or religious people ignoring science and believing that science rejects religion (Barmania \& Reiss, 2020).

In addition, almost all religions practise mass gatherings as a form of religious observance. Even though such observances can be practised at home, religious leaders prefer to conduct mass gatherings due to systems that have been established over centuries (Hopkins \& Reicher, 2020). Some religious leaders believe long-term abstinence from such events can lead to a reduction in the devotion of devotees towards their religion. However, collective events have many repercussions that can pose a significant health risk to the community (Hopkins \& Reicher, 2020; Memish et al., 2019). Therefore, there should be a fine balance, and the number of people who can participate in mass gatherings should be restricted and governed by health authorities, and if conditions permit, to allow attendance in limited capacities. However, some religious subgroups have extreme viewpoints. It is exceedingly difficult to convince their members of new messages. Therefore, preventive activities are unlikely to receive their support 
even though the message has great health relevance (Chatters, 2000). Furthermore, some religions believe in the purity of consumer products. Therefore, if a product is not up to the standard of purity according to recommendations made by the doctrines of their faith, there will be a tendency against the consumption of it. Particularly if a vaccine is not manufactured according to the purity standards taught by religion, vaccine hesitancy can occur, leading to refusal of vaccination (Khoo et al., 2020). In the event of the rapid international rollout of COVID-19 vaccination campaigns, vaccine hesitancy remains a significant challenge requiring urgent attention (Razai et al., 2021).

\section{Future Directions}

Religion can be described as a potent, long-standing, and pervasive social force for the prevention of outbreaks. The spread of COVID-19 can be slowed down or exaggerated by social power. Although religion has not been formally categorised as a social determinant of health, to a greater or lesser degree, it affects many people's lives and social activities (Barmania \& Reiss, 2020). There are existing, active, and influential networks of religious leaders and communities working in partnership with global, regional, national, and native public health initiatives (Silvestri \& Mayall, 2015). However, to make their contributions effective, they need to be advocated for by relevant authorities. Importantly, religious leaders need to be included in the decision-making process (Barmania \& Reiss, 2020). Moreover, all religious leaders need to work towards a common goal. However, the norms of society are affected by the vaccines and new therapeutics that will come on-stream soon (Razai et al., 2021). Therefore, there needs to be a balance between religious traditions and interpretations and the government's responsibility to protect the health of the many by taking maximum benefit from societal power (Barmania \& Reiss, 2020; Hong \& Handal, 2020). Both short-term and long-term attention to minimise the effects of events around the COVID-19 crisis in Sri Lanka needs to be addressed by all parties. Therefore, there is a need for collaboration between government, civil society, and religious communities. Moreover, recognising the policy implications of sensitive cultural practices and prompt regulations is needed to minimise ethnic discrimination, spreading of disinformation, misinformation, and hate speeches (Levush, 2019). For that, collaboration among religious communities plays a central role in addressing the dire consequences of misinformation among communities. The positive stories not brought to public attention need to be highlighted by government, civil society, and religious communities.

\section{Limitations}

One of the significant limitations of this model is the inability to get support from extreme religious groups. This is because the model has no provision for involving those groups in discussions. Furthermore, there may be occasions of changing the original health messages since there is no monitoring mechanism. Another potential limitation was the long-term sustainability of the model due to the non-availability of identified government funding mechanisms. 


\section{Conclusions}

This paper highlights a novel COVID-19 prevention model with mobilisation of religious leaders that can be implemented in low resource settings. Our experience from Sri Lanka demonstrates the feasibility of implementing this model to mitigate the disastrous situation following the COVID-19 outbreak. However, there needs to be adequate public health infrastructure at the grassroot level for this model to succeed. In conclusion, promoting multi-stakeholder partnerships with religious groups and integrating health promotion channels and resources in response to COVID-19 and future communicable diseases would benefit many countries.

\section{Funding None.}

\section{Declarations}

Conflict of interest None declared.

\section{References}

Arruda, G. A. (2020). The impact of the pandemic on the conception of poverty, discourse, and praxis of Christian religious communities in Brazil from the perspective of their local leaders. International Journal of Latin American Religions, 4(2), 380-401. https://doi.org/10.1007/s41603-020-00122-2

Barmania, S., \& Reiss, M. J. (2020). Health promotion perspectives on the COVID-19 pandemic: The importance of religion. Global Health Promotion, 28(1), 15-22. https://doi.org/10.1177/17579 75920972992

BBC News. (2021, March 2). COVID-19: Sri Lanka chooses remote island for burials. https://www.bbc. com/news/world-asia-56249805

Berkley Center for Religion Peace \& World Affairs. (2020). The COVID-19 emergency in Sri Lanka: Strengths and challenges. https://berkleycenter.georgetown.edu/publications/the-covid-19-emerg ency-in-sri-lanka-strengths-and-challenges/pdf_download/en

Bhanot, D., Singh, T., Verma, S. K., \& Sharad, S. (2021). Stigma and discrimination during COVID-19 pandemic. Frontiers in Public Health. https://doi.org/10.3389/fpubh.2020.577018

Binnicker, M. J. (2020). Challenges and controversies to testing for COVID-19. Journal of Clinical Microbiology. https://doi.org/10.1128/jcm.01695-20

Brownson, R. C., Seiler, R., \& Eyler, A. A. (2010). Measuring the impact of public health policys. Preventing Chronic Disease, 7(4)(A77). https://www.ncbi.nlm.nih.gov/pmc/articles/PMC2901575/

Chatters, L. M. (2000). Religion and health: Public health research and practice. Annual Review of Public Health, 21(1), 335-367. https://doi.org/10.1146/annurev.publhealth.21.1.335

Fernando, D. (2000). Health care systems in transition III. Sri Lanka, Part I. An overview of Sri Lanka's health care system. Journal of Public Health, 22(1), 14-20. https://doi.org/10.1093/pubmed/22.1.14

Gilmore, B., Ndejjo, R., Tchetchia, A., de Claro, V., Mago, E., Diallo, A. A., Lopes, C., \& Bhattacharyya, S. (2020). Community engagement for COVID-19 prevention and control: A rapid evidence synthesis. BMJ Global Health, 5(10), e003188. https://doi.org/10.1136/bmjgh-2020-003188

Health Promotion Bureau-Ministry of Health Sri Lanka, UNICEF, \& Sarvodaya. (2021). Community engagement during COVID-19 vaccine rollout (1st ed.). UNICEF. https://www.hpb.health.gov.lk/ en/news-single/23

Heward-Mills, N. L., Atuhaire, C., Spoors, C., Pemunta, N. V., Priebe, G., \& Cumber, S. N. (2018). The role of faith leaders in influencing health behaviour: A qualitative exploration on the views of Black African Christians in Leeds, United Kingdom. Pan African Medical Journal. https://doi.org/10. 11604/pamj.2018.30.199.15656 
Hong, B. A., \& Handal, P. J. (2020). Science, religion, government, and SARS-CoV-2: A time for synergy. Journal of Religion and Health, 59(5), 2263-2268. https://doi.org/10.1007/s10943-020-01047-y

Hopkins, N., \& Reicher, S. (2020). Mass gatherings, health, and well-being: From risk mitigation to health promotion. Social Issues and Policy Review, 15(1), 114-145. https://doi.org/10.1111/sipr. 12071

Kawachi, I. (2019). Invited commentary: Religion as a social determinant of health. American Journal of Epidemiology, 189(12), 1461-1463. https://doi.org/10.1093/aje/kwz204

Khoo, Y. S. K., Ghani, A. A., Navamukundan, A. A., Jahis, R., \& Gamil, A. (2019). Unique product quality considerations in vaccine development, registration and new program implementation in Malaysia. Human Vaccines \& Immunotherapeutics, 16(3), 530-538. https://doi.org/10.1080/21645 515.2019.1667206

Knight, D., Dudenkov, D. V., \& Cheshire, W. P. (2021). Religion in the US during the time of a pandemic: A medical perspective. Journal of Religion and Health. https://doi.org/10.1007/s10943-021-01366-8

Levush, R. (2019). Government Responses to Disinformation on Social Media Platforms: Argentina, Australia, Canada, China, Denmark, Egypt, European Union, France, Germany, India, Israel, Mexico, Russian Federation, Sweden, United Arab Emirates, United Kingdom. Libraries at University of Nebraska-Lincoln. https://digitalcommons.unl.edu/scholcom/178/

Majra, D., Benson, J., Pitts, J., \& Stebbing, J. (2020). SARS-CoV-2 (COVID-19) superspreader events. Journal of Infection, 82(1), 36-40. https://doi.org/10.1016/j.jinf.2020.11.021

Marston, C., Renedo, A., \& Miles, S. (2020). Community participation is crucial in a pandemic. The Lancet, 395(10238), 1676-1678. https://doi.org/10.1016/s0140-6736(20)31054-0

Memish, Z. A., Steffen, R., White, P., Dar, O., Azhar, E. I., Sharma, A., \& Zumla, A. (2019). Mass gatherings medicine: Public health issues arising from mass gathering religious and sporting events. The Lancet, 393(10185), 2073-2084. https://doi.org/10.1016/s0140-6736(19)30501-X

Oyo-Ita, A., Bosch-Capblanch, X., Ross, A., Oku, A., Esu, E., Ameh, S., Oduwole, O., Arikpo, D., \& Meremikwu, M. (2021). Effects of engaging communities in decision-making and action through traditional and religious leaders on vaccination coverage in Cross River State, Nigeria: A clusterrandomised control trial. PLoS ONE, 16(4), e0248236. https://doi.org/10.1371/journal.pone.02482 36

Pan, D., Sze, S., Minhas, J. S., Bangash, M. N., Pareek, N., Divall, P., Williams, C. M., Oggioni, M. R., Squire, I. B., Nellums, L. B., Hanif, W., Khunti, K., \& Pareek, M. (2020). The impact of ethnicity on clinical outcomes in COVID-19: A systematic review. EClinicalMedicine, 23, 100404. https:// doi.org/10.1016/j.eclinm.2020.100404

Pennisi, E. (2011, August 23). Does Religion Influence Epidemics? Science. https://www.science.org/ news/2011/08/does-religion-influence-epidemics

Potvin, L., \& Jones, C. M. (2011). Twenty-five years after the Ottawa Charter: The critical role of health promotion for public health. Canadian Journal of Public Health, 102(4), 244-248. https://doi.org/ $10.1007 / \mathrm{bf03404041}$

Press Trust of India. (2021, April 28). Hindu temple officials in Sri Lanka's Jaffna arrested for holding festival amid COVID-19 surge. The New Indian Express. https://www.newindianexpress.com/world/ 2021/apr/28/hindu-temple-officials-in-sri-lankas-jaffna-arrested-for-holding-festival-amid-covid-19surge-2295904.html

Quadri, S. A. (2020). COVID-19 and religious congregations: Implications for spread of novel pathogens. International Journal of Infectious Diseases, 96, 219-221. https://doi.org/10.1016/j.ijid.2020. 05.007

Ranawana, A. (2020, March 21). Jaffna Philadelphia Church parishioners asked to self-quarantine after Pastor gets COVID19. EconomyNext. https://economynext.com/jaffna-philadelphia-church-paris hioners-asked-to-self-quarantine-after-pastor-gets-covid19-60782/

Razai, M. S., Chaudhry, U. A. R., Doerholt, K., Bauld, L., \& Majeed, A. (2021). Covid-19 vaccination hesitancy. British Medical Journal. https://doi.org/10.1136/bmj.n1138

Ruijs, W. L., Hautvast, J. L., Kerrar, S., van der Velden, K., \& Hulscher, M. E. (2013). The role of religious leaders in promoting acceptance of vaccination within a minority group: A qualitative study. BMC Public Health. https://doi.org/10.1186/1471-2458-13-511

Saeed, F., Mihan, R., Mousavi, S. Z., Reniers, R. L., Bateni, F. S., Alikhani, R., \& Mousavi, S. B. (2020). A narrative review of stigma related to infectious disease outbreaks: What can be learned in the face of the Covid-19 pandemic? Frontiers in Psychiatry. https://doi.org/10.3389/fpsyt.2020.565919 
Sarmiento, P. J. D. (2020). Changing landscapes of death and burial practices: Public health response in time of COVID-19 pandemic. Journal of Public Health, 43(2), e267-e268. https://doi.org/10.1093/ pubmed/fdaa211

Silvestri, S. \& Mayall, J. (2015). The role of religion in conflict and peacebuilding. British Academy. https://www.thebritishacademy.ac.uk/documents/325/Role-of-religion-in-conflict-peacebuild ing_0_0.pdf

Soleimanvandi Azar, N., Irandoost, S. F., Ahmadi, S., Xosravi, T., Ranjbar, H., Mansourian, M., \& Yoosefi Lebni, J. (2021). Explaining the reasons for not maintaining the health guidelines to prevent COVID-19 in high-risk jobs: a qualitative study in Iran. BMC Public Health. https://doi.org/10. 1186/s12889-021-10889-4

Tony Blair Institute for Global Change. (2020, May 7). Covid-19: Guide for Governments Working with Religious Leaders to Support Public-Health Measures. Joint Learning Initiative on Faith and Local Communities. https://jliflc.com/resources/covid-19-guide-for-governments-working-with-religiousleaders-to-support-public-health-measures/

UCA News. (2021, May 14). Sri Lanka cancels major Buddhist, Muslim festivals. Ucanews.com. https:// www.ucanews.com/news/sri-lanka-cancels-major-buddhist-muslim-festivals/92460\#

van den Broucke, S. (2020). Why health promotion matters to the COVID-19 pandemic, and vice versa. Health Promotion International, 35(2), 181-186. https://doi.org/10.1093/heapro/daaa042

Wijesinghe, M. S. D., Weerasinghe, W. M. P. C., Gunawardana, I., Perera, S. N. S., \& Karunapema, R. P. P. (2021). Acceptance of COVID-19 vaccine in Sri Lanka: Applying the health belief model to an online survey. Asia Pacific Journal of Public Health, 33(5), 598-602. https://doi.org/10.1177/10105 395211014975

World Health Organization. (2020a). Infection prevention and control for the safe management of a dead body in the context of COVID-19: interim guidance. World Health Organization. WHO. https:// apps.who.int/iris/handle/10665/334156?locale-attribute=ar\&order=desc\&query=Infection\%20pre vention $\% 20$ and $\% 20$ control $\% 20$ for $\% 20$ the $\% 20$ safe $\% 20$ management $\% 20$ of $\% 20$ a $\% 20$ dead $\% 20$ body $\%$ 20 in $\% 20$ the $\% 20$ context $\% 20$ of $\% 20$ COVID-19\&scope $=\&$ sort_by $=$ score $\& \mathrm{rpp}=10 \&$ search-result $=$ true

World Health Organization. (2020b). Practical considerations and recommendations for religious leaders and faith-based communities in the context of COVID-19: interim guidance. WHO. https://apps. who.int/iris/bitstream/handle/10665/331707/WHO-2019-nCoV-Religious_Leaders-2020.1-eng.pdf

Yip, W., Ge, L., Ho, A. H. Y., Heng, B. H., \& Tan, W. S. (2021). Building community resilience beyond COVID-19: The Singapore way. The Lancet Regional Health - Western Pacific, 7, 100091. https:// doi.org/10.1016/j.lanwpc.2020.100091

Yoosefi Lebni, J., Ziapour, A., Mehedi, N., \& Irandoost, S. F. (2021). The role of clerics in confronting the COVID-19 crisis in Iran. Journal of Religion and Health, 60(4), 2387-2394. https://doi.org/10. 1007/s10943-021-01295-6

Publisher's Note Springer Nature remains neutral with regard to jurisdictional claims in published maps and institutional affiliations. 


\section{Authors and Affiliations}

Millawage Supun Dilara Wijesinghe ${ }^{1}\left[\right.$ ] Vinya S. Ariyaratne ${ }^{2}$.

Balangoda Muhamdiramlage Indika Gunawardana' .

R. M. Nayani Umesha Rajapaksha ${ }^{1} \cdot$ W. M. Prasad Chathuranga Weerasinghe ${ }^{1}$. Praveen Gomez ${ }^{3}$. Sahani Chandraratna ${ }^{4}$. Thirupathy Suveendran ${ }^{4}$. R. P. Palitha Karunapema ${ }^{1}$

Vinya S. Ariyaratne

vinya@sarvodaya.org

Balangoda Muhamdiramlage Indika Gunawardana

bmigunawardana@gmail.com

R. M. Nayani Umesha Rajapaksha

drnayani2020@gmail.com

W. M. Prasad Chathuranga Weerasinghe

prasad.chathuranga@gmail.com

Praveen Gomez

praveen@adtlanka.org

Sahani Chandraratna

sahanic@who.int

Thirupathy Suveendran

suveendrant@who.int

R. P. Palitha Karunapema

palitha_66@yahoo.com

1 Health Promotion Bureau, No. 02, Kynsey Road, Colombo 08, Sri Lanka

2 Sarvodaya Shramadana Movement, No.98, Rawathawatta Road, Moratuwa, Sri Lanka

3 Alliance Development Trust, No.95, Galle Road, Dehiwala, Sri Lanka

4 World Health Organization, No. 05, Anderson Road, Colombo, Sri Lanka 